\title{
A theory of bidirectional judgments
}

\author{
ROBERT F. FAGOT \\ University of Oregon, Eugene, Oregon 97403
}

\begin{abstract}
This paper is concerned with a scaling theory for "bidirectional" judgments, for which the order of judgment is reversible, as in fractional and multiple ratio estimation judgments. With the assumption that judgments are mediated by perceived relations of pairs of stimuli, the theory is developed for judgments of comparison stimuli in relation to standards, taking explicit account of the location of the comparison stimulus relative to the standard. The theory of bidirectional judgments, based on a theory of relative judgment by Fagot $(1978,1979)$, entails a partial nesting of models characterized by a progressive weakening of the constraints placed on the structure of the data. The weakest model, the relative bias/directional standard (RBDS) model, allows each standard to have two biasing effects, depending on the location of the standard above or below the comparison stimulus. Tests of the theory were carried out on the ratio estimation of brightness and weight data of Engen and Levy (1955) and the part-sum estimation data of Goude (1962). Only the RBDS model was found acceptable for all three data sets.
\end{abstract}

This paper is concerned with the development of a scaling theory for bidirectional judgments. Judgments are defined as bidirectional if the order of judgment is reversible. For example, denote, by $R_{a b}$, the estimation of the ratio of the magnitude of stimulus a to the magnitude of stimulus $b$. Then the order of judgment may be reversed, with $\mathbf{R}_{\mathrm{ba}}$ denoting the estimated ratio of $b$ to $a$.

Then, for each presentation pair $(a, b)$ and some judgment, $\mathrm{J}$, bidirectional theory is concerned with empirically distinguishable judgments, $\mathrm{J}_{\mathrm{ab}}$ and $\mathrm{J}_{\mathrm{ba}}$. Judgments made in one direction only will be called unidirectional. A precise definition of bidirectional judgments will be given after presentation of some theory.

The approach taken in this paper is that judgments are mediated by perceived relations of pairs of stimuli. We shall be concerned with judgments of a comparison stimulus in relation to a standard stimulus. Surprisingly, research in psychophysics on the effect of standards has been limited for the most part to studies of the effects on the power function (Engen \& Levy, 1955; Engen \& Ross, 1966; Jones \& Woskow, 1966; Macmillan, Moschetto, Bialostozky, \& Engel, 1974; Poulton, 1968; Ross \& DiLollo, 1970). But surely this is bypassing the more basic measurement question of the effect of standards on judgments? For example, if standards bias judgments of comparison stimuli, are there differential biasing effects depending on the location of the standard above or below the comparison stimulus? If there are, and given a model that attempts to characterize the effects of

This project was supported in whole or in part by BRSG Grant S07RR07080 awarded by the Biomedical Research Support Grant Program, Division of Research Resources, National Institutes of Health. standards on bidirectional judgments of comparison stimuli, what conditions on observed bidirectional judgments are entailed? That is, what are the testable consequences of the theory that must be satisfied prior to scale construction?

These and other questions are addressed by the theory of bidirectional judgments to be presented, based on a theory of relative judgment by Fagot $(1978,1979)$. First the theory will be outlined briefly, followed by further theoretical development that takes explicit account of bidirectionality. Finally, the theory will be tested with ratio estimation (based on brightness and weight data from Engen \& Levy, 1955) and part-sum estimation of weight data (Goude, 1962).

\section{THEORY}

The theory (Fagot, 1978, 1979) deals with any set of judgments $J_{a b}$ for which there exists a response transformation $J_{a b}^{*}$ that is a function of sensory ratios $\Psi_{\mathrm{a}} / \Psi_{\mathrm{b}}$ and possible bias parameters. Three specific model equations were analyzed:

$$
\begin{aligned}
& \mathrm{J}_{\mathrm{ab}}^{*}=\Psi_{\mathrm{a}} / \Psi_{\mathrm{b}}, \\
& \mathrm{J}_{\mathrm{ab}}^{*}=\alpha \Psi_{\mathrm{a}} / \Psi_{\mathrm{b}}, \\
& \mathrm{J}_{\mathrm{ab}}^{*}=\alpha_{\mathrm{b}} \Psi_{\mathrm{a}} / \Psi_{\mathrm{b}},
\end{aligned}
$$

where $\alpha$ and $\alpha_{\mathrm{b}}$ are bias parameters and $\Psi$ is the scaling function (a ratio scale). Equations 1, 2, and 3 are referred to as the classical (C), constant bias (CB), and relative bias $(\mathrm{RB})$ models, respectively.

Three structural conditions, each imposing constraints on the observed judgments, are entailed for all $a, b, x, y$ : 


\section{Ratio Consistency (C1):}

$$
\mathrm{J}_{\mathrm{ab}}^{*}=\mathrm{J}_{\mathrm{ax}}^{*} \mathrm{~J}_{\mathrm{xb}}^{*}=\mathrm{J}^{*}{ }_{\mathrm{ay}} \mathrm{J}^{*}{ }_{\mathrm{yb}},
$$

Product Constancy (C2):

$$
\mathrm{J}_{\mathrm{ax}}^{*} \mathrm{~J}_{\mathrm{xb}}^{*}=\mathrm{J}_{\mathrm{ay}}^{*} \mathrm{~J}_{\mathrm{yb}}^{*},
$$

\section{Ratio Constancy (C3):}

$$
\mathrm{J}_{\mathrm{ax}}^{*} / \mathrm{J}_{\mathrm{bx}}^{*}=\mathrm{J}_{\mathrm{ay}}^{*} / \mathrm{J}_{\mathrm{by}}^{*} \text {. }
$$

It can be shown that Equation 1-the $\mathrm{C}$ modelentails $\mathrm{Cl}, \mathrm{C2}$, and $\mathrm{C} 3$ (but $\mathrm{C} 2$ and $\mathrm{C} 3$ are entailed by $\mathrm{C} 1$ ). $\mathrm{Cl}$ is written in $\mathrm{x}$ and $\mathrm{y}$ form to make explicit that $\mathrm{C} 2$ is nested in $\mathrm{C} 1$. Equation 2-the $\mathrm{CB}$ model-entails $\mathrm{C} 2$ and $\mathrm{C} 3$; and Equation 3-the RB model-entails C3 (Fagot, 1978).

To apply the theory to a given scaling model, it is only necessary to derive a response transformation $\mathrm{J}^{*}$, satisfying Equation 1, 2, or 3 (Fagot, 1979).

The theory is illustrated via two examples, ratio estimation and unidimensional similarity judgments. For ratio estimation, the basic assumption generally made is that $R_{a b}=\Psi_{a} / \Psi_{b}$. This equation is of the same form as Equation 1 , and hence the response transformation is simply $J_{a b}^{*}=R_{a b}$ and the theory of $J_{a b}^{*}$ applies directly to the $R_{a b}$. For example, $C 1$ is $\mathbf{R}_{\mathrm{ab}}=\mathbf{R}_{\mathrm{ax}} \mathbf{R}_{\mathrm{xb}}$. Explication of the theory applied to ratio estimation, along with empirical tests, is presented by Fagot (1978).

Eisler and Ekman (1959) proposed a simple model of similarity judgments for unidimensional attributes:

$$
\mathrm{S}_{\mathrm{ab}}=\Psi_{\mathrm{a}} / 1 / 2\left(\Psi_{\mathrm{a}}+\Psi_{\mathrm{b}}\right) \quad\left(\Psi_{\mathrm{a}}<\Psi_{\mathrm{b}}\right),
$$

where $S_{a b}$ is the judged similarity between the two percepts and $0 \leqslant S_{a b} \leqslant 1$. In order to find the response transformation $J_{a b}^{*}$, we must find $S_{a b}^{*}$ such that $S_{a b}^{*}=\Psi_{a} / \Psi_{b}$, conforming to Equation 1 . This is done by solving Equation 7 for $\Psi_{a} / \Psi_{b}$, which is $\Psi_{\mathrm{a}} / \Psi_{\mathrm{b}}=\mathrm{S}_{\mathrm{ab}} /\left(2-\mathrm{S}_{\mathrm{ab}}\right)$. Hence, the response transformation is $\mathrm{J}_{\mathrm{ab}}^{*}=\mathrm{S}_{\mathrm{ab}}^{*}=\mathrm{S}_{\mathrm{ab}}\left(2-\mathrm{S}_{\mathrm{ab}}\right)$ and the theory on $\mathrm{J}_{\mathrm{ab}}^{*}$ applies to $\mathrm{S}_{\mathrm{ab}}^{*}$ (not $\mathrm{S}_{\mathrm{ab}}$ ). Application of the theory to this model is presented in Fagot (1979) along with empirical tests.

These examples show how to find the response transformation and demonstrate the wide applicability of the theory to any judgment model for which a response transformation exists satisfying Equation 1,2 , or 3 .

The theory of relative judgment represented by Equations 1-6 applies to both the bidirectional case in which both $J_{a b}$ and $J_{b a}$ are defined as well as the unidirectional case in which only one $J$ applies. The extensive data base for ratio estimation and similarity judgments examined by Fagot $(1978,1979)$ consisted of unidirectional judgments. In the case of ratio estimation, this was because the standard was always the larger stimulus of the presentation pair. The Eisler and Ekman (1959) similarity model assumed that judgments were symmetric; that is, $S_{a b}=S_{b a}$. Hence, in neither case were the complications of bidirectional theory needed.

Equations 1-6 are not restricted to the case of unidirectional judgments, as applied by Fagot (1978) to ratio estimation. If judgments are bidirectional, however, the number of test cases for the structural conditions is substantially increased, as will be shown below.

No special problems arise in the application of the $\mathrm{C}$ or CB model to the bidirectional case. However, one extension is required relating the bidirectional judgments. For the $\mathrm{C}$ model, Equation 1 entails $\mathrm{J}_{\mathrm{ba}}^{*}=\Psi_{\mathrm{b}} / \Psi_{\mathrm{a}}$, and hence a reciprocal relation, $\mathrm{J}_{\mathrm{ab}}^{*}=$ $1 / \mathrm{J}_{\mathrm{ba}}^{*}$, which we state in product form ${ }^{1}$ :

$$
\mathrm{J}_{\mathrm{ab}}^{*} \mathrm{~J}_{\mathrm{ba}}^{*}=1 \text {. }
$$

We are now in a position to give a more precise definition of bidirectional judgments. Let $J_{a b}$ be any judgment of stimulus a relative to stimulus $b$. Then $J_{\mathrm{ab}}^{*}$ and $\mathrm{J}_{\mathrm{ba}}^{*}$ are bidirectional judgments if (1) $\mathrm{J}_{\mathrm{ab}}$ and $\mathrm{J}_{\mathrm{ba}}$ are empirically distinguishable and (2) $\mathrm{J}_{\mathrm{ab}}^{*}$ is a reciprocal function of $\mathrm{J}_{\mathrm{ba}}^{*}$; in particular, if responses are unbiased, then Equation 8 holds.

The requirement of a reciprocal relation distinguishes bidirectionality from other order effects, such as a position effect. For example, suppose $R_{a b}$ denotes the ratio estimation of $a$ to $b$ when $a$ is on the left, and $R_{b a}$ when $b$ is on the left. Then, in the $a b-$ sence of bias, both $\mathbf{R}_{\mathrm{ab}}$ and $\mathbf{R}_{\mathrm{ba}}$ estimate the sensory ratio $\Psi_{\mathrm{a}} / \Psi_{\mathrm{b}}$-that is, $\mathrm{R}_{\mathrm{ab}}=\Psi_{\mathrm{a}} / \Psi_{\mathrm{b}}$ and $\mathrm{R}_{\mathrm{ba}}=\Psi_{\mathrm{a}} / \Psi_{\mathrm{b}}$, therefore $\mathbf{R}_{\mathrm{ab}}=\mathbf{R}_{\mathrm{ba}}$-and hence the reciprocal relation does not hold. It would be possible to model both bidirectionality and a position effect, but that line will not be pursued here.

If judgments are biased, the reciprocal relation will include bias parameters, the precise form of which will depend on the model. For the CB model, Equation 2 entails that the product form of the reciprocal rule is

$$
\mathrm{J}_{\mathrm{ab}}^{*} \mathrm{~J}_{\mathrm{ba}}^{*}=a^{2} \text {. }
$$

In applying the RB model to bidirectional judgments, we need to consider certain special cases, corresponding to different possible sources of bias. Equation 3 can be used to model the effect of standards, associating a bias $\alpha_{b}$ with each standard (with the bias operating on the comparison stimulus). For bidirectional judgments, Equation 3 will be referred to as the relative bias/standard (RBS) model. Note that for the RBS model we also have $\mathrm{J}_{\mathrm{ba}}^{*}=\alpha_{\mathrm{a}} \Psi_{\mathrm{b}} / \Psi_{\mathrm{a}}$, 
and hence the product form of the reciprocal rule is

$$
\mathrm{J}_{\mathrm{ab}}^{*} \mathrm{~J}_{\mathrm{ba}}^{*}=\alpha_{\mathrm{a}} \alpha_{\mathrm{b}} .
$$

Another possible source of bias in bidirectional judgments is the direction of the standard relative to the comparison stimulus. Let $\alpha_{H}$ denote the bias parameter if the standard is higher (larger in magnitude) than the comparison stimulus, and $\alpha_{L}$ denote the bias parameter if the standard is lower. Then the representation taking into account solely the directional effect is given by the following special case of Equation 3:

$$
\begin{aligned}
& \mathrm{J}_{\mathrm{ab}}^{*}=\alpha_{\mathrm{H}} \Psi_{\mathrm{a}} / \Psi_{\mathrm{b}} \\
& \mathrm{J}_{\mathrm{ba}}^{*}=\alpha_{\mathrm{L}} \Psi_{\mathrm{b}} / \Psi_{\mathrm{a}}
\end{aligned}
$$

and the product form of the reciprocal relation is

$$
\mathrm{J}_{\mathrm{ab}}^{*} \mathrm{~J}_{\mathrm{ba}}^{*}=\alpha_{\mathrm{H}} \alpha_{\mathrm{L}} \text {. }
$$

Equations 11 will be referred to as the relative bias/ directional (RBD) model.

Finally, the representation taking account of the combined effects of standard and direction is

$$
\begin{aligned}
& \mathrm{J}_{\mathrm{ab}}^{*}=\alpha_{\mathrm{bH}} \Psi_{\mathrm{a}} / \Psi_{\mathrm{b}} \\
& \mathrm{J}_{\mathrm{ba}}^{*}=\alpha_{\mathrm{aL}} \Psi_{\mathrm{b}} / \Psi_{\mathrm{a}}
\end{aligned}
$$

and

$$
\mathrm{J}_{\mathrm{ab}}^{*} \mathrm{~J}_{\mathrm{ba}}^{*}=\alpha_{\mathrm{aL}} \alpha_{\mathrm{bH}} \text {. }
$$

Equations 13 will be referred to as the relative bias/directional standard (RBDS) model. The RBDS model allows each standard to have two biasing effects, depending on the location of the standard relative to the comparison stimulus.

To place the $C$ and $C B$ models in perspective, we see that the $\mathrm{C}$ model assumes that none of the biasing effects exist, whereas the CB model assumes that all biases are equal, that is, that the bias does not depend on the location of the standard.

The bias parameters for all models are derived from one or more forms of the function $\mathrm{J}^{\prime}=\mathrm{J}_{\mathrm{ab}}^{*} \mathrm{~J}_{\mathrm{bc}}^{*}$ ' $\mathrm{J}_{\mathrm{ac}}^{*}$. For each triple, there are six forms of $\mathrm{J}^{\prime}$ for bidirectional judgments since there are three pairs $(a, c)$, and each pair has two directions. In Table 1, the first column lists the six forms of $J^{\prime}$ and the remaining columns indicate, for each model, which bias param-

\begin{tabular}{|c|c|c|c|c|c|}
\hline \multirow[b]{2}{*}{ Form of $\mathrm{J}^{\prime}$} & \multicolumn{5}{|c|}{ Model (Equation) } \\
\hline & $\begin{array}{c}C \\
(1)\end{array}$ & $\begin{array}{l}\text { CB } \\
(2)\end{array}$ & $\begin{array}{l}\text { RBD } \\
\text { (11) }\end{array}$ & $\begin{array}{c}\text { RBS } \\
(3)\end{array}$ & $\begin{array}{c}\text { RBDS } \\
\text { (13) }\end{array}$ \\
\hline (1) $\mathrm{J}_{\mathrm{ab}}^{*} \mathrm{~J}_{\mathrm{bc}}^{*} / \mathrm{J}_{\mathrm{ac}}^{*}=$ & 1 & $\alpha$ & $a_{H}$ & $\alpha_{\mathbf{b}}$ & $\alpha_{\mathbf{b H}}$ \\
\hline (2) $\mathrm{J}_{\mathrm{cb}}^{*} \mathrm{~J}_{\mathrm{ba}}^{*} / \mathrm{J}_{\mathrm{ca}}^{*}=$ & 1 & $\alpha$ & $\alpha_{L}$ & $\alpha_{\mathrm{b}}$ & $\alpha_{b L}$ \\
\hline (3) $\mathrm{J}_{\mathrm{ba}}^{*}{ }_{\mathrm{jac}}^{*} / \mathrm{J}_{\mathrm{bc}}^{*}=$ & 1 & $\alpha$ & ${ }^{\alpha} \mathrm{L}$ & $\alpha_{\mathbf{a}}$ & $\alpha_{\mathrm{aL}}$ \\
\hline (4) $\mathrm{J}_{\mathrm{ca}}^{*} \mathrm{~J}_{\mathrm{ab}}^{*} / \mathrm{J}_{\mathrm{cb}}^{*}=$ & 1 & $\alpha$ & $\alpha_{\mathbf{H}}$ & $\alpha_{\mathbf{a}}$ & $\alpha_{\mathrm{aL}} \alpha_{\mathrm{bH}} / \alpha_{\mathrm{bL}}$ \\
\hline (5) $\mathrm{J}_{\mathrm{ac}}^{*} \mathrm{~J}_{\mathbf{c b}}^{*} / \mathrm{J}_{\mathrm{ab}}^{*}=$ & 1 & $\alpha$ & $\alpha_{\mathbf{L}}$ & $\alpha_{\mathbf{c}}$ & $\alpha_{\mathrm{cH}} \alpha_{\mathrm{bL}} / \alpha_{\mathrm{bH}}$ \\
\hline (6) $\mathrm{J}_{\mathrm{bc}}^{*} \mathrm{~J}_{\mathrm{ca}}^{*} / \mathrm{J}_{\mathbf{b a}}^{*}=$ & 1 & $\alpha$ & $\alpha_{H}$ & $\alpha_{\mathbf{c}}$ & $\alpha_{\mathbf{c H}}$ \\
\hline
\end{tabular}
eter corresponds to each form of $\mathrm{J}^{\prime}$.

The second column of Table 1 states that, for each form, $\mathrm{J}^{\prime}=1$, which is a statement of $\mathrm{Cl}$. Note that, for each triple, there are six forms of $\mathrm{Cl}$ for bidirectional judgments (and hence six test cases), but only
Table 1

Formulas for Bias Parameters (for all $\mathbf{a}<\mathbf{b}<\mathbf{c}$ )

one for unidirectional judgments (form 1 or form 2 , depending on the direction of the judgments). $\mathrm{Cl}$ places the strongest constraints on the structure of the data and is entailed solely by the $\mathrm{C}$ model.

The bias parameters in Table 1 may be derived in the following manner. Consider form 2 and write the algebraic identity $\left(\Psi_{\mathrm{c}} / \Psi_{\mathrm{b}}\right)\left(\Psi_{\mathrm{b}} / \Psi_{\mathrm{a}}\right)=\left(\Psi_{\mathrm{c}} / \Psi_{\mathrm{a}}\right)$. To find the bias parameter for the RBDS model, we note, from Equation 13 , that $\left(\Psi_{\mathrm{c}} / \Psi_{\mathrm{b}}\right)=\left(J_{\mathrm{cb}}^{*} / \alpha_{\mathrm{bL}}\right),\left(\Psi_{\mathrm{b}} / \Psi_{\mathrm{a}}\right)$ $=\left(\mathrm{J}_{\mathrm{ba}}^{*} / \alpha_{\mathrm{aL}}\right)$, and $\left(\Psi_{\mathrm{c}} / \Psi_{\mathrm{a}}\right)=\mathrm{J}_{\mathrm{ca}}^{*} / \alpha_{\mathrm{aL}}$. Therefore, $\left(\mathrm{J}_{\mathrm{cb}}^{*} /\right.$ $\left.\alpha_{\mathrm{bL}}\right)\left(\mathrm{J}_{\mathrm{ba}}^{*} / \alpha_{\mathrm{aL}}\right)=\mathrm{J}_{\mathrm{ca}}^{*} / \alpha_{\mathrm{aL}}$ and $\alpha_{\mathrm{bL}}=\mathrm{J}_{\mathrm{cb}}^{*} \mathrm{~J}_{\mathrm{ba}}^{*} / \mathrm{J}_{\mathrm{ca}}^{*}$, as shown in Table 1.

Since the RBS model ignores direction, the subscript " $L$ " is deleted and, for form 2, $J_{\mathrm{cb}}^{*} \mathrm{~J}_{\mathrm{ba}}^{*}$ ' $\mathrm{J}_{\mathrm{ca}}^{*}=\alpha_{\mathrm{b}}$, as shown in column 5 . And, since the RBD model assumes that only direction need be considered, the subscript " $b$ " is deleted, as indicated in column 4. Finally, since the CB model assumes that bias is constant over standard and direction, all subscripts are deleted, as indicated in column 3 . In a similar manner, the other bias parameters may be derived for the other forms in Table 1.

Note that forms 4 and 5 in Table 1 do not define a unique parameter for the RBDS model. However, deletion of appropriate subscripts leads to unique parameters for the other models based on forms 4 and 5.

\section{Parametric Forms of C2 and C3}

It can be inferred from Equation 5 that, for the bidirectional case, $\mathrm{C} 2$ is a system of 12 equations for each tetrad of stimuli, and all 12 equations are entailed by both the $\mathrm{C}$ and CB models. The RBD model provides a means of classifying this system into five forms of $\mathrm{C} 2$, as shown in Table 2.

The $(\mathrm{H})$ after form 1 and the $(\mathrm{L})$ after form 2 in Table 2 indicate that all judgments entering into forms 1 and 2 are made with respect to a high or low standard, respectively. For form 3, a high and low standard enters on each side of the equation.

In forms 4 and 5 , each side is operated on by the reciprocal of a different $\mathrm{RBD}$ bias parameter, and, 
Table 2

Parametric Forms of C2 Entailed by RBD Model

\begin{tabular}{lll}
\hline Form & \multicolumn{1}{c}{$\mathrm{C} 2(\mathrm{a}<\mathrm{b}<\mathrm{c}<\mathrm{d})$} & $\mathrm{N}$ \\
\hline $1(\mathrm{H})$ & $\mathrm{J}_{\mathbf{a b}}^{*} \mathrm{~J}_{\mathbf{b d}}^{*}=\mathrm{J}_{\mathbf{a c}}^{*} \mathrm{~J}_{\mathbf{c d}}^{*}$ & 1 \\
$2(\mathrm{~L})$ & $\mathrm{J}_{\mathbf{d b}}^{*} \mathrm{~J}_{\mathbf{b a}}^{*}=\mathrm{J}_{\mathbf{d c}}^{*} \mathrm{~J}_{\mathbf{c a}}^{*}$ & 1 \\
$3(\mathrm{LH})$ & $\mathrm{J}_{\mathbf{b a}}^{*} \mathrm{~J}_{\mathbf{a c}}^{*}=\mathrm{J}_{\mathbf{b d}}^{*} \mathrm{~J}_{\mathbf{d c}}^{*}$ & 6 \\
4 & $\left(1 / \alpha_{\mathrm{L}}\right) \mathrm{J}_{\mathbf{c b}}^{*} \mathrm{~J}_{\mathbf{b a}}^{*}=\left(1 / \alpha_{\mathrm{H}}\right) \mathrm{J}_{\mathbf{c d}}^{*} \mathrm{~J}_{\mathbf{d a}}^{*}$ & 2 \\
5 & $\left(1 / \alpha_{\mathrm{H}}\right) \mathrm{J}_{\mathbf{a b}}^{*} \mathrm{~J}_{\mathbf{b c}}^{*}=\left(1 / \alpha_{\mathbf{L}}\right) \mathrm{J}_{\mathbf{a d}}^{*} \mathrm{~J}_{\mathbf{d c}}^{*}$ & 2 \\
\hline
\end{tabular}

Note-Deleting $\alpha_{L}$ and $\alpha_{H}$ transforms Table 2 to five forms of $C 2 . N=$ number in each form per tetrad.

hence, only forms 1-2-3 are entailed by the RBD model. Forms 4 and 5 are, of course, converted to C2 forms by setting $\alpha_{H}=\alpha_{L}=\alpha$, with $\alpha$ canceling out.

Table 2 makes explicit five forms of C2 when $\alpha_{L}$ and $\alpha_{H}$ are deleted from forms 4 and 5 . Hence, when we speak of "forms of $\mathrm{C} 2$," we will be referring to the forms listed in Table 2 with bias parameters deleted in forms 4 and 5 . The value of this classification lies in the operation of different effective biases in each form, together with its use in choosing between the CB and RBD models.

To see that the RBD model entails forms 1-3 of $\mathrm{C} 2$, it is necessary only to extend the definitions of $\alpha_{L}$ and $\alpha_{H}$ in Table 1 to four stimuli. For example, $\alpha_{\mathrm{H}}=\left(\mathrm{J}_{\mathrm{ab}}^{*} \mathrm{~J}_{\mathrm{bd}}^{*} / \mathrm{J}_{\mathrm{ad}}^{*}\right)=\left(\mathrm{J}_{\mathrm{ac}}^{*} \mathrm{~J}_{\mathrm{cd}}^{*} / \mathrm{J}_{\mathrm{ad}}^{*}\right)$, from which form 1 of Table 2 follows. Similar reasoning shows that forms 2 and 3 of Table 2 are entailed by the RBD model.

To see that form 4 of $\mathrm{C} 2$ is not entailed by the RBD model (i.e., $\mathrm{J}_{\mathrm{cb}}^{*} \mathrm{~J}_{\mathrm{ba}}^{*} \neq \mathrm{J}_{\mathrm{cd}}^{*} \mathrm{~J}_{\mathrm{da}}^{*}$ ), note that $\alpha_{\mathrm{L}}=$ $\mathrm{J}_{\mathrm{cb}}^{*} \mathrm{~J}_{\mathrm{ba}}^{*} / \mathrm{J}_{\mathrm{ca}}^{*}$ and $\alpha_{\mathrm{H}}=\mathrm{J}_{\mathrm{cd}}^{*} \mathrm{~J}_{\mathrm{da}}^{*} / \mathrm{J}_{\mathrm{ca}}^{*}$. Solving both equations for $\mathrm{J}_{\mathrm{ca}}^{*}$ and equating resultants, we get the parametric form of form 4 indicated in Table 2, and hence in general $\mathrm{J}_{\mathrm{cb}}^{*} \mathrm{~J}_{\mathrm{ba}}^{*} \neq \mathrm{J}_{\mathrm{cd}}^{*} \mathrm{~J}_{\mathrm{da}}^{*}$. Similar reasoning gives the parametric form 5 of $\mathrm{C} 2$, showing that $\mathrm{J}_{\mathrm{ab}}^{*} \mathrm{~J}_{\mathrm{bc}}^{*} \neq \mathrm{J}_{\mathrm{ad}}^{*} \mathrm{~J}_{\mathrm{dc}}^{*}$.

Setting $\alpha_{\mathrm{L}}=\alpha_{\mathrm{H}}=1\left(\mathrm{C}\right.$ model) and $\alpha_{\mathrm{L}}=\alpha_{\mathrm{H}}=\alpha(\mathrm{CB}$ model) in forms 4 and 5 shows that all forms of $C_{2}$ are entailed by the $\mathrm{C}$ and $\mathrm{CB}$ models. It is easy to show that no forms of $\mathrm{C} 2$ are entailed by the RBS or RBDS models.

The last column of Table 2 gives the number of $\mathrm{C} 2$ equations for each form per tetrad of stimuli. For the unidirectional case, only form 1 or form 2 applies, resulting in only one test case per tetrad.

Table 3 presents the parametric forms of $\mathrm{C} 3$ entailed by the RBDS model. The (H), (L), and (LH) after forms 1-2-3 have the same interpretation as in Table 2. Deleting all $\alpha$ from the last three forms transforms Table 3 into a table of six $\mathrm{C} 3$ forms.

The Table 3 classification is useful in exhibiting the $\mathrm{C} 3$ entailments of the various models: The presence of bias parameters in forms 4,5 , and 6 indicates that only forms 1,2 , and 3 of $\mathrm{C} 3$ are entailed by the RBDS model. Deleting $b, c$ from the bias parameters (only direction counts) indicates that forms $1,2,3$, and 4 are entailed by the RBD model, but not forms 5 and 6 . Deleting $L$ and $H$ (direction does not count) indicates that all forms of $\mathrm{C} 3$ are entailed by the RBS model, since all bias parameters cancel. Setting all parameters equal to one or $\alpha$ shows that all forms of $\mathrm{C} 3$ are entailed by the $\mathrm{C}$ and $\mathrm{CB}$ models.

For unidirectional judgments, only form 1 or form 2 of C3 applies (depending on direction of judgment), resulting in only one test case per tetrad, as in the case of $\mathrm{C} 2$. Of course, in the unidirectional case, the RBD and RBDS models are not applicable, since the directional factor is not operative.

The complete list of entailments for each model is given in Table 4.

Note the partial nesting of models exhibited by these entailments, with the $\mathrm{C}$ model placing the strongest constraints on the structure of the data and the RBDS model, the weakest. A complete nesting would exist if the RBD model entailed all forms of C3.

The bidirectional theory will be tested using two judgmental tasks, ratio estimation and part-sum estimation. It was eariier shown that, for ratio estimation, the response transformation is $\mathrm{J}_{\mathrm{ab}}^{*}=\mathbf{R}_{\mathrm{ab}}$, and, hence, one need only make this substitution to test the bidirectional model for ratio estimation judgments $\mathbf{R}_{\mathrm{ab}}$ and $\mathbf{R}_{\mathrm{ba}}$. However, for part-sum estimation we need to describe the method, state the judgmental model, and find the response transformation $\mathbf{J}_{\mathbf{a b}}^{*}$.

\section{Part-Sum Estimation}

The part-sum estimation method was apparently introduced by Goude (1962), and is similar to the constant-sum method (Comrey, 1950). In the partsum method, stimuli are presented in pairs, and the task of the subject is to judge the percent magnitude of each member of the pair to the sum of the two magnitudes. The basic difference between the partsum and constant-sum methods is that in the part-

Table 3

Parametric Forms of C3 Entailed by RBDS Model

\begin{tabular}{|c|c|}
\hline Form & $\mathrm{C} 3(\mathrm{a}<\mathrm{b}<\mathrm{c}<\mathrm{d})$ \\
\hline $1(\mathrm{H})$ & $\mathrm{J}_{\mathbf{a c}}^{*} / \mathrm{J}_{\mathrm{bc}}^{*}=\mathrm{J}_{\mathbf{a d}}^{*} / \mathrm{J}_{\mathbf{b d}}^{*}$ \\
\hline $2(\mathrm{~L})$ & $\mathrm{J}_{\mathrm{ca}}^{*} / \mathrm{J}_{\mathrm{da}}^{*}=\mathrm{J}_{\mathrm{cb}}^{*} / \mathrm{J}_{\mathrm{ab}}^{*}$ \\
\hline $3(\mathrm{LH})$ & $\mathrm{J}_{\mathrm{ba}}^{*} / \mathrm{J}_{\mathrm{ca}}^{*}=\mathrm{J}_{\mathrm{bd}}^{*} / \mathrm{J}_{\mathrm{cd}}^{*}$ \\
\hline 4 & $\left(\alpha_{\mathrm{bL}} / \alpha_{\mathrm{bH}}\right) \mathrm{J}_{\mathrm{ab}}^{*} / \mathrm{J}_{\mathrm{db}}^{*}=\left(\alpha_{\mathrm{cL}} / \alpha_{\mathrm{cH}}\right) \mathrm{J}_{\mathrm{ac}}^{*} / \mathrm{J}_{\mathrm{dc}}^{*}$ \\
\hline 5 & $\mathrm{~J}_{\mathbf{b a}}^{*} / \mathrm{J}_{\mathbf{d a}}^{*}=\left(\alpha_{\mathbf{c L}} / \alpha_{\mathbf{c H}}\right) \mathrm{J}_{\mathbf{b c}}^{*} / J_{\mathbf{d c}}^{*}$ \\
\hline 6 & $\left(\alpha_{\mathrm{bL}} / \alpha_{\mathrm{bH}}\right) \mathrm{J}_{\mathbf{a b}}^{*} / \mathrm{J}_{\mathbf{c b}}^{*}=\mathrm{J}_{\mathbf{a d}}^{*} / \mathrm{J}_{\mathbf{c d}}^{*}$ \\
\hline
\end{tabular}

Note-Deleting all $\alpha$ transforms Table 3 to six forms of C3. 
Table 4

Model Entailments

\begin{tabular}{|c|c|c|c|c|c|c|}
\hline \multirow{2}{*}{$\begin{array}{l}\text { Structural } \\
\text { Condition }\end{array}$} & \multirow[b]{2}{*}{ Forms } & \multicolumn{5}{|c|}{ Model } \\
\hline & & $\mathrm{C}$ & $\mathrm{CB}$ & RBD & RBS & RBDS \\
\hline $\mathrm{C} 1$ & All & $\mathrm{X}$ & & & & \\
\hline $\mathrm{C} 2$ & $\begin{array}{l}1-2-3 \\
4-5\end{array}$ & $\begin{array}{l}X \\
X\end{array}$ & $\begin{array}{l}X \\
X\end{array}$ & $X$ & & \\
\hline $\mathrm{C} 3$ & $\begin{array}{l}1-2-3 \\
4 \\
5-6\end{array}$ & $\begin{array}{l}X \\
X \\
X\end{array}$ & $\begin{array}{l}X \\
X \\
X\end{array}$ & $\begin{array}{l}X \\
X\end{array}$ & $\begin{array}{l}X \\
X \\
X\end{array}$ & $\mathrm{X}$ \\
\hline
\end{tabular}

Note-X indicates row condition entailed by column model.

sum method, two ratio judgments are made for each presentation pair, whereas for the constant-sum method (divide 100 points between the two stimuli), only one ratio is entailed by the instructions.

The part-sum judgmental model, assuming no response bias, is simply

$$
P_{\mathrm{ab}}=\Psi_{\mathrm{a}} /\left(\Psi_{\mathrm{a}}+\Psi_{\mathrm{b}}\right),
$$

where $P_{a b}$ is the percent judgment of the comparison stimulus a relative to the sum of stimuli $a$ and $b$, and $\Psi$ is the scaling function. Equation 15 can be written in the form

$$
\Psi_{\mathrm{a}} / \Psi_{\mathrm{b}}=\mathrm{P}_{\mathrm{ab}} /\left(1-\mathrm{P}_{\mathrm{ab}}\right)
$$

Therefore, the required response transformation is

$$
J_{a b}^{*}=P_{a b}^{*}=P_{a b} /\left(1-P_{a b}\right)
$$

and

$$
\mathrm{P}^{*}{ }_{\mathrm{ab}}=\Psi_{\mathrm{a}} / \Psi_{\mathrm{b}}
$$

$P_{a b}$ and $P_{b a}$ are empirically distinguishable, and $\mathrm{P}_{\mathrm{ba}}^{*}=\Psi_{\mathrm{b}} / \Psi_{\mathrm{a}}$. Therefore, the reciprocal relation $\mathrm{P}_{\mathrm{ab}}^{*} \mathrm{P}_{\mathrm{ba}}^{*}=1$ holds for the $\mathrm{C}$ model, and part-sum estimation satisfies the formal requirements of bidirectional judgments. Bias parameters are introduced as in Equations 1-2-3-11-13, and with the substitution $\mathrm{J}_{\mathrm{ab}}^{*}=\mathrm{P}_{\mathrm{ab}}^{*}$ the theory of bidirectional judgments is directly applicable to $P_{a b}^{*}$ (not $P_{a b}$ ).

In the interpretation of bidirectional theory as applied to ratio estimation and part-sum estimation, two differences should be noted. First, for ratio estimation the standard is explicit, whereas for part-sum estimation the standard is implicit and assumed: In treating $\mathrm{P}_{\mathrm{ab}}^{*}$ and $\mathrm{P}_{\mathrm{ba}}^{*}$ as bidirectional, the first stimulus is the comparison and the second the assumed standard stimulus. Second, for ratio estimation the bidirectional theory applies directly to the elementary judgments $\mathbf{R}_{\mathrm{ab}}$ and $\mathbf{R}_{\mathrm{ba}}$, whereas for part-sum estimation the theory applies to the transformed responses $\mathrm{P}_{\mathrm{ab}}^{*}$ and $\mathrm{P}_{\mathrm{ba}}^{*}$.
There are two reasons why part-sum estimation is worthy of serious attention. First, to try to answer the basic question, is there a magnitude scale (for a given attribute) that mediates a diversity of judgmental tasks such as ratio and part-sum estimation? The second reason refers to a nice property of the method: it is unit-free. By this is meant that the judgments do not depend on the particular unit used, as can be seen from Equation 15, since units cancel. Ratio estimation is also unit-free, whereas magnitude estimation (without a standard) is not. Thus, for ratio estimation and part-sum estimation, the theory is indifferent to changes of unit on every trial (or to different subjects using a different unit if a group scale is being constructed), whereas for magnitude estimation, the subject must retain the same unit on every trial or, if subjects are aggregated, all subjects must use the same unit.

\section{RESULTS AND DISCUSSION}

Tests of the models were based on the ratio estimation of brightness (gray patches) and weight data of Engen and Levy (1955); and the part-sum estimation of weight data of Goude (1962). In the remaining discussion, ratio estimation of brightness and weight will be abbreviated $\mathrm{RE}(\mathrm{B})$ and $\mathrm{RE}(\mathrm{W})$, respectively; and part-sum estimation of weight will be abbreviated PS(W).

Engen and Levy (1955) used nine stimuli and three standards for each of the two attributes. The standards were the third (low), fifth (middle), and seventh (high) stimuli. Each of the remaining eight stimuli were judged relative to each of the three standards, twice by each of 15 subjects. Estimates of the $R_{\mathbf{a b}}$ were taken as the median of the 15 subjects $(30$ judgments).

In the PS(W) data of Goude (1962), there were five stimuli and each stimulus served as both comparison and standard. Estimates of the $P_{a b}$ were the arithmetic means of six subjects.

\section{Tests of Structural Conditions}

The structural conditions were tested in the form of the following null hypotheses:

$$
\begin{aligned}
& \mathrm{H}_{0}(\mathrm{C} 1): \mathrm{J}_{\mathrm{ab}}^{*}=\mathrm{J}_{\mathrm{a} 1}^{*} \mathrm{~J}_{1 \mathrm{~b}}^{*}=\mathrm{J}_{\mathrm{a} 2}^{*} \mathrm{~J}_{2 \mathrm{~b}}^{*}=\ldots \mathrm{J}_{\mathrm{ak}}^{*} \mathrm{~J}_{\mathrm{kb}}^{*} \\
& \mathrm{H}_{0}(\mathrm{C} 2): \mathrm{J}_{\mathrm{a} 1}^{*} \mathrm{~J}_{1 \mathrm{~b}}^{*}=\mathrm{J}_{\mathrm{a} 2}^{*} \mathrm{~J}_{2 \mathrm{~b}}^{*}=\ldots \mathrm{J}_{\mathrm{ak}}^{*} \mathrm{~J}_{\mathrm{kb}}^{*} \\
& \mathrm{H}_{0}(\mathrm{C} 3)^{2}: \mathrm{J}_{\mathrm{a} 1}^{*} / \mathrm{J}_{\mathrm{b} 1}^{*}=\mathrm{J}_{\mathrm{a} 2}^{*} / \mathrm{J}_{\mathrm{b} 2}^{*}=\ldots \mathrm{J}_{\mathrm{ak}}^{*} / \mathrm{J}_{\mathrm{bk}}^{*} .
\end{aligned}
$$

The "equivalents" of the equations of the null hypotheses constituted the levels of the first factor in a two-way repeated measures analysis of variance design. The second factor was "stimulus sets," con- 
sisting of triples of stimuli for $\mathrm{Cl}$ and tetrads for $\mathrm{C} 2$ and C3. Real differences in the levels of the second factor are expected, and are of no interest. The statistical tests were carried out on the first factor, for each structural condition separately. The dependent variable was $\log$ observation $\left(\log \mathrm{J}^{*}\right)$ with one observation per cell. The analysis also provided an estimate of the intraclass correlation coefficient (ICC), which is a measure of the agreement or consistency of the equivalents of the structural condition ${ }^{3}$ (Bartko, 1976; Shrout \& Fleiss, 1979).

For the PS(W) data of Goude (1962), each of the n stimuli served as a standard (and comparison) stimulus. In the case of $\mathrm{C} 1$ for the Goude data, $k=n-2$, and the number of equivalents (levels of the first factor) was $k+1=4$. The number of stimulus sets (levels of the second factor) for $\mathrm{Cl}$ was $2\left(\frac{\mathfrak{n}}{2}\right)=$ $n(n-1)=20$.

For the RE(B) and RE(W) data of Engen and Levy (1955), only three standards were used and $n=9$. For $\mathrm{C} 1, \mathrm{k}=2$, and the number of equivalents was $\mathrm{k}+1=3$. The number of stimulus sets for $\mathrm{Cl}$ was 18 .

In order to choose among the CB, RBD, RBS, and RBDS models, it is necessary to test subsets of the forms of $\mathrm{C} 2$ and $\mathrm{C} 3$ as defined in Tables 2 and 3. When $\mathrm{C} 2$ and $\mathrm{C} 3$ were organized by form, the number of equivalents was $k=2$.

For the complete pair-comparison presentation used in the PS(W) data, the number of stimulus sets was 60 for $\mathrm{C2}$ and 30 for C3. For the $\operatorname{RE}(B)$ and RE(W) data, the number of stimulus sets were: for $\mathrm{C} 2,18$ for all forms combined and 12 for forms 1-2-3 (entailed by RBD model); and for C3, 63 for all forms combined and 19 for forms 1-2-3 (entailed by the RBDS model).

The model entailments listed in Table 4 provide a guide to the way in which the structural conditions will be used to evaluate and compare models. For example, a rejection of $\mathrm{Cl}$ entails immediately a rejection of the $\mathrm{C}$ model; a comparison of the fit of forms 1-2-3 vs. forms 4-5 of $C 2$ provides a basis for choosing between the RBD and CB models; and a compari- son of the fit of forms 1-2-3 vs. 4-5-6 of $\mathrm{C3}$ provides a basis for choosing between the RBDS and the RBS models.

Three criteria will be used to analyze and compare structural conditions: the analysis of variance test described above, the ICC as a measure of agreement or consistency of the equivalents of a structural condition, and an analysis of systematic errors. The fit of the data to the various reciprocal relations also will be analyzed.

The analysis of variance results, including the ICC measures, are given in Table 5.

Table 5 shows that $\mathrm{Cl}$ is rejected for all three sets of data, providing sufficient basis for a rejection of the $\mathrm{C}$ model. Of particular interest are the nature of systematic errors in $\mathrm{C} 1$, to be considered after analysis of C3.

As Table 4 shows, $\mathrm{C} 2$ provides a basis for testing the CB and RBD models, although the RBD model also entails forms $1-4$ of $C 3$. Table 5 shows that $\mathrm{C} 2$ (all forms) is rejected for PS(W) and RE(B), but not for $\operatorname{RE}(W)$. Forms 1-3 of C2 are rejected for PS(W), but not for $\mathrm{RE}(\mathrm{W})$ or $\mathrm{RE}(\mathrm{B})$. These somewhat equivocal findings are clarified by means of appropriate graphs and an analysis of systematic errors.

Figure 1 shows a plot of $\log R_{a y} R_{y b}$ as a function of $\log R_{a x} R_{x b}(x<y)$ for $R E(B)$. The dominant trend is clearly $R_{a x} R_{x b}<R_{a y} R_{y b}$, with proportions $\hat{p}=.889$ for all forms and $\hat{p}=.833$ for forms 1-2-3. A test of $\mathrm{H}_{0}: \mathrm{p}=.5$ is rejected at the .01 level for all forms and at the .05 level for forms 1-2-3.

A plot of $\log \mathrm{P}_{\mathrm{ay}}^{*} \mathrm{P}_{\mathrm{yb}}^{*}$ as a function of $\log \mathrm{P}_{\mathrm{ax}}^{*} \mathrm{P}_{\mathrm{xb}}^{*}$ for PS(W) (not presented) gives similar results. The proportions for $\mathrm{P}_{\mathrm{ax}}^{*} \mathrm{P}_{\mathrm{xb}}^{*}<\mathrm{P}_{\mathrm{ay}}^{*} \mathrm{P}_{\mathrm{yb}}^{*}$ are $\hat{\mathrm{p}}=.733$ for all forms and $\hat{p}=.800$ for forms $1-2-3$, with significance levels of $\mathrm{p}=.001$ in both cases.

For PS(W), the ANOVA test and the analysis of systematic errors agree: both the CB and RBD models must be rejected.

For RE(B), both tests agree that the CB model must be rejected. And, although the ANOVA test is not significant for forms $1-2-3$ of $\mathrm{C} 2$, Figure 1 is

Table 5

Intraclass Correlation Coefficient (ICC) and Analysis of Variance Test (F)

\begin{tabular}{|c|c|c|c|c|c|c|c|c|c|c|c|}
\hline \multirow{3}{*}{$\begin{array}{l}\text { Con- } \\
\text { dition }\end{array}$} & \multirow{3}{*}{$\begin{array}{c}\text { Entailed by } \\
\text { Model: }\end{array}$} & \multirow[b]{3}{*}{ Forms } & \multirow{2}{*}{\multicolumn{3}{|c|}{$\begin{array}{c}\text { Goude (1962) } \\
\text { PS(W) }\end{array}$}} & \multicolumn{6}{|c|}{ Engen and Levy (1955) } \\
\hline & & & & & & \multicolumn{3}{|c|}{$\mathrm{RE}(\mathrm{W})$} & \multicolumn{3}{|c|}{ RE(B) } \\
\hline & & & ICC & $\mathrm{F}$ & $\mathrm{df}$ & $\mathrm{ICC}$ & $\mathbf{F}$ & df & ICC & $\mathbf{F}$ & $\mathrm{df}$ \\
\hline $\mathrm{C} 1$ & $\mathrm{C}$ & & .996 & $7.17 \dagger \dagger$ & 3,57 & .938 & $3.34^{* *}$ & 2,34 & .925 & $3.36 * *$ & 2,34 \\
\hline $\mathrm{C} 2$ & $\begin{array}{l}\text { CB } \\
\text { RBD }\end{array}$ & $\begin{array}{l}\text { All } \\
1-2-3\end{array}$ & $\begin{array}{l}.995 \\
.996\end{array}$ & $\begin{array}{l}22.58+\dagger \\
21.04+t\end{array}$ & $\begin{array}{l}1,59 \\
1,39\end{array}$ & $\begin{array}{l}.929 \\
.924\end{array}$ & $\begin{array}{l}4.41^{*} \\
2.52^{*}\end{array}$ & $\begin{array}{l}1,17 \\
1,11\end{array}$ & $\begin{array}{l}.911 \\
.888\end{array}$ & $\begin{array}{l}5.13^{* *} \\
1.59^{*}\end{array}$ & $\begin{array}{l}1,17 \\
1,11\end{array}$ \\
\hline C3 & $\begin{array}{l}\text { RBS } \\
\text { RBDS } \\
\text { RBS } \\
\text { RBD }\end{array}$ & $\begin{array}{l}\text { All } \\
1-2-3 \\
4-5-6 \\
1-2-3-4\end{array}$ & $\begin{array}{l}.982 \\
.957 \\
.970 \\
.990\end{array}$ & $\begin{array}{l}.23^{*} \\
.08^{*} \\
.69^{*} \\
.13^{*}\end{array}$ & $\begin{array}{l}1,29 \\
1,14 \\
1,14 \\
1,19\end{array}$ & $\begin{array}{r}.947 \\
1.000 \\
.861 \\
.952\end{array}$ & $\begin{array}{c}20.18 \dagger \dagger \\
9.05 \dagger \\
20.86 \dagger \dagger \\
10.96 \dagger\end{array}$ & $\begin{array}{l}1,62 \\
1,18 \\
1,43 \\
1,38\end{array}$ & $\begin{array}{l}.924 \\
.976 \\
.818 \\
.919\end{array}$ & $\begin{array}{r}.23^{*} \\
1.28^{*} \\
.00^{*} \\
.14^{*}\end{array}$ & $\begin{array}{l}1,62 \\
1,18 \\
1,43 \\
1,38\end{array}$ \\
\hline
\end{tabular}

*Not significant. $\quad * * p<.05 . \quad t p<.01 . \quad+t p<.001$. 


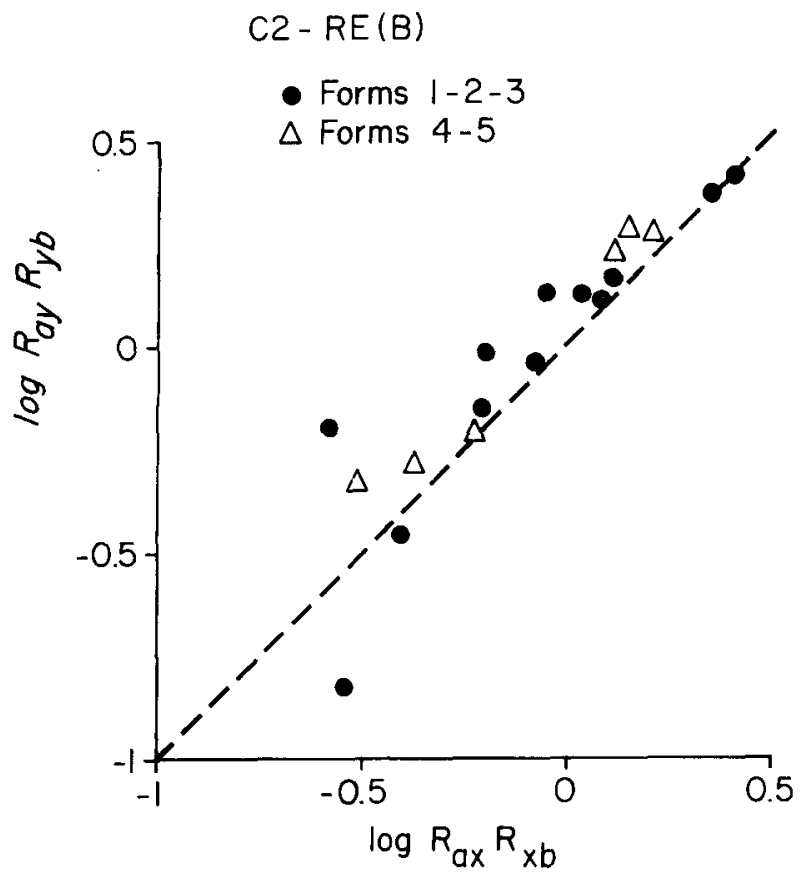

Figure 1. C2: $\log R_{2 y} R_{y b}$ as a function of $\log R_{a x} R_{x b}(x<y)$ for RE(B) with forms 1-2-3 and 4-5 separately identified. The dashed line is the identity line $\log R_{a y} R_{y b}=\log R_{x x} R_{x b}$. Data from Engen and Levy (1955).

persuasive evidence for the rejection of the RBD model.

The status of the CB and RBD models for RE(W) is less clear, although the ANOVA test failed to reject in either case. As in the previous two cases, an analysis of systematic errors helps to clarify.

Figure 2 shows a plot of $\log R_{a y} R_{y b}$ as a function of $\log \mathbf{R}_{\mathrm{ax}} \mathbf{R}_{\mathrm{xb}}$ for $\mathrm{RE}(\mathrm{W})$.

In spite of the ANOVA test result, Figure 2 shows that the weight data fit poorly for $\mathrm{C} 2$, although the systematic trend is not the simple one exhibited in Figure 1. The reverse trend from the lower to upper range in Figure 1 was tested by means of a runs test. Results were (see Siegel, 1956: one-sample runs test, Table F): For all forms, $n_{1}=9, n_{2}=9, r=3$; for forms 1-2-3, $n_{1}=6, n_{2}=6, r=3$. In both cases, the hypothesis of randomness of order is rejected $(p<.05)$. The observed systematic trend of $R_{a x} R_{x b}>R_{a y} R_{y b}$ at the lower end of the range and the reverse trend at the upper end is therefore tenable. It is on the basis of Figure 2 and the consequent runs test that the CB and RBD models may be rejected for $R E(W)$. In conclusion to this part of the analysis, the CB and RBD models are rejected for all three data sets.

Condition C3 provides a means of choosing between the RBS and RBDS models. The RBDS model places the weakest constraints on the structure of the data of all the models considered, requiring only that forms $1-2-3$ of $\mathrm{C} 3$ be satisfied. The stronger RBS model demands, in addition, that forms 4-5-6 be satisfied. Hence, to make a choice between the two models, we need to compare results for forms 1-2-3 as against forms 4-5-6.

Consider the results for PS(W) first. Table 5 shows that none of the four cases of C3 may be rejected, providing no basis for a choice between the RBS and RBDS model. Figure 3 shows a plot of the product form of $\mathrm{C} 3$ for $\mathrm{PS}(\mathrm{W})$ : $\log \mathrm{P}_{\mathrm{ad}}^{*} \mathrm{P}_{\mathrm{bc}}^{*}$ as a function of $\log \mathrm{P}_{\mathrm{ac}}^{*} \mathrm{P}_{\mathrm{bd}}^{*}$ for forms 1-2-3 (panel $A$ ) and forms 4-5-6 (panel B) separately. ${ }^{5}$

Figure 3 for PS(W) shows a reasonable fit in both panels. There is the suggestion of a systematic trend in panel B, but a runs test, as applied to the data of Figure 2, was not significant $\left(n_{1}=5, n_{2}=10, r=6\right)$ : $p>.05$. The ICCs are comparable in both panels, in fact, slightly lower for the RBDS model. We conclude that the $\mathrm{C} 3$ part-sum data are consistent with the stronger RBS model.

Table 5 also shows that none of the four cases of C3 may be rejected for the $R E(B)$ data. Figure 4 shows a graph of $\mathrm{C} 3$ for $\mathrm{RE}(\mathrm{B})$ following the same form as Figure 3.

Inspection of Figure 4 indicates a better fit to the data in panel $A$, consistent with the much higher ICC: .976 for the RBDS model (forms 1-2-3), and .818 for the RBS model (forms 4-5-6). On the basis of Figure 4 and the relative ICCs, the RBDS model is judged superior to the RBS model for the RE(B) data.

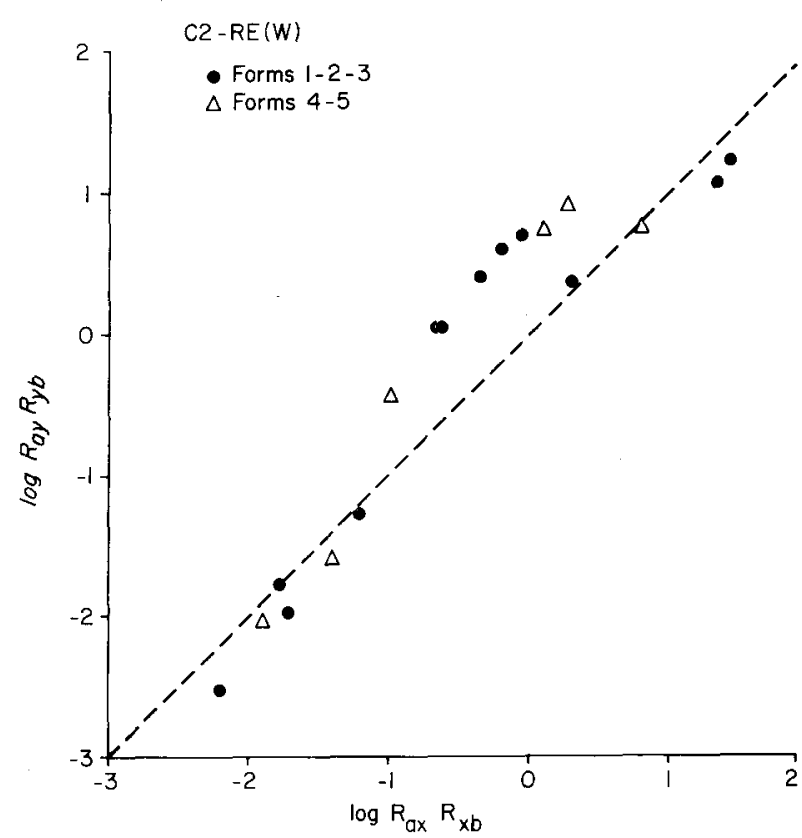

Figure 2. C2: $\log \mathbf{R}_{\mathrm{ay}} \mathbf{R}_{\mathrm{yb}}$ as a function of $\log \mathbf{R}_{\mathrm{ax}} \mathbf{R}_{\mathrm{ab}}(x<y)$ for $\operatorname{RE}(W)$ with forms $1-2-3$ and $4-5$ separately identified. The dashed line is the identity line $\log R_{a y} R_{y b}=\log R_{a x} R_{x b}$. Data from Engen and Levy (1955). 

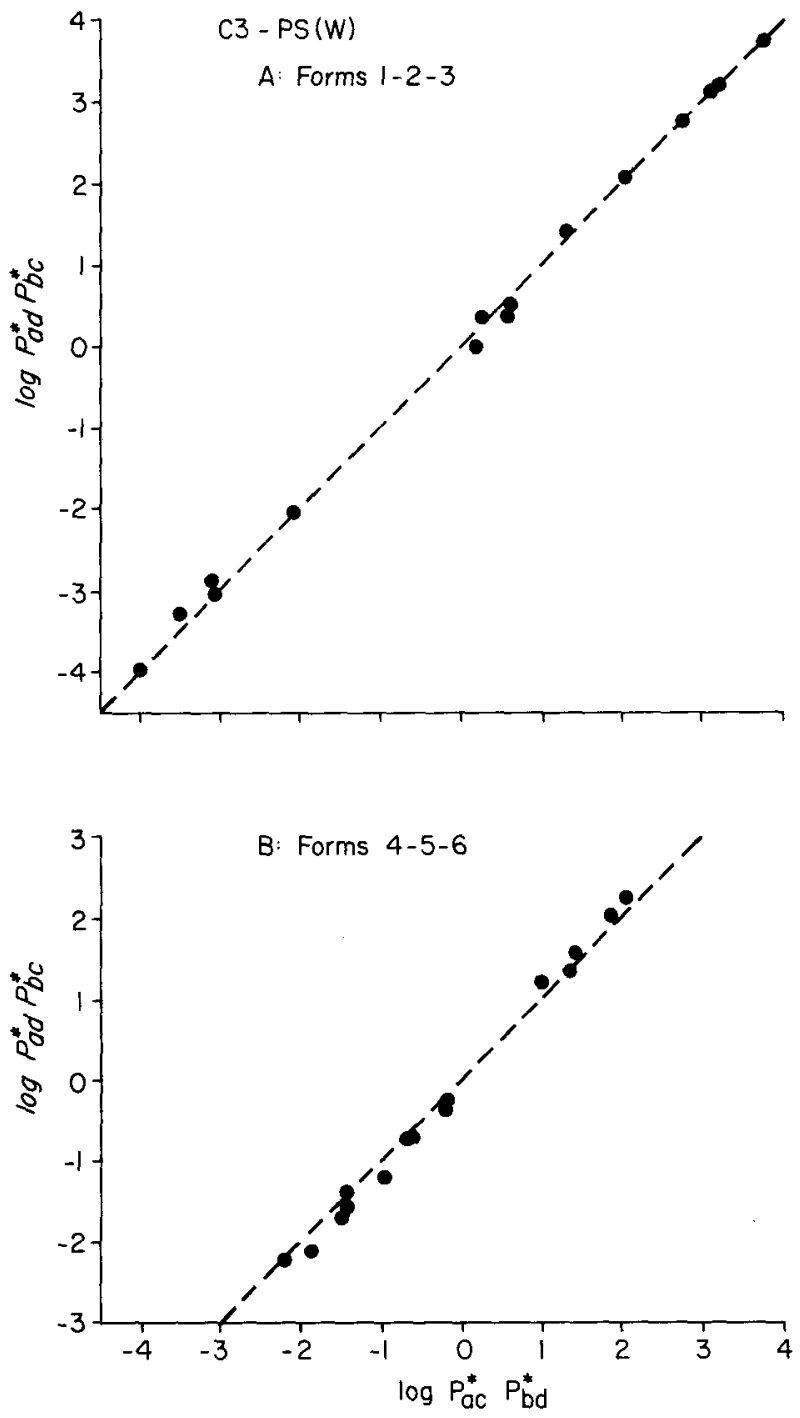

Figure 3. C3: $\log P_{*}^{*} P_{b e}^{*}$ as a function of $\log P_{*}^{*} P_{b}^{*}$ for $P S(W)$. Panel A, forms 1-2-3; panel B, forms 4-5-6. The dashed line is the identity line $\log P_{d d}^{*} P_{b c}^{*}=\log P_{a c}^{*} P_{b d}^{*}$. Data from Goude (1962).

Table 5 shows that all four cases of $\mathrm{C} 3$ are statistically significant for RE(W). Figure 5 shows a graph of $C 3$ for $R E(W)$ following the same form as Figures 3 and 4.

Inspection of Figure 5 shows that the fit of $\mathrm{C} 3$ is extremely good for the RBDS model (panel A) but poor for the RBS model (panel B). The statistically significant result for the RBDS model in Table 5 is due to the fact that the mean squared error is extremely small. The mean squared error for forms 4-5-6 is 121 times that for forms 1-2-3. Comparing forms 1-2-3 for $R E(W)$ and $R E(B)$, the mean squared error for $\operatorname{RE}(B)$ is 7.3 times that of $R E(W)$, so that the less favorable result for $R E(W)$ is due to very small mean squared error and not large mean squared deviations. ${ }^{6}$ It is to be noted that for $\mathrm{RE}(\mathrm{W}), \mathrm{ICC}=$
1.000 for forms $1-2-3$, whereas $\mathrm{ICC}=.861$ for forms 4-5-6. On the basis of Figure 5 and the ICCs, the RBDS model fares much better than the RBS model for $\operatorname{RE}(W)$.

\section{Reciprocal Relations}

Figure 6 shows a plot of $1 / \mathrm{J}_{\mathrm{ba}}^{*}$ as a function of $\mathrm{J}_{\mathrm{ab}}^{*}$ for all three data sets. Note that there are only three data points each for RE(W) and RE(B).

The $\mathrm{C}$ model (Equation 7) requires that the function be a straight line through the origin with unit slope (solid line). These data do not conform well to this requirement.

The CB model (Equation 8) requires that the function be a straight line through the origin with slope $1 / \alpha^{2}$. This is the dashed line in Figure 6 for PS(W) only, and there is little improvement. Figure 6 is consistent with the rejection of the $\mathrm{C}$ and $\mathrm{CB}$ models based on failure of $\mathrm{C} 1$ and $\mathrm{C} 2$, respectively.

Figure 7 shows a plot of $\alpha_{\mathrm{aL}} / \mathrm{J}_{\mathrm{ba}}^{*}$ as a function of $\mathrm{J}_{\mathrm{ab}}^{*} / \alpha_{\mathrm{bH}}$ for all three data sets. The RBDS model (Equation 13) requires that the function be a straight
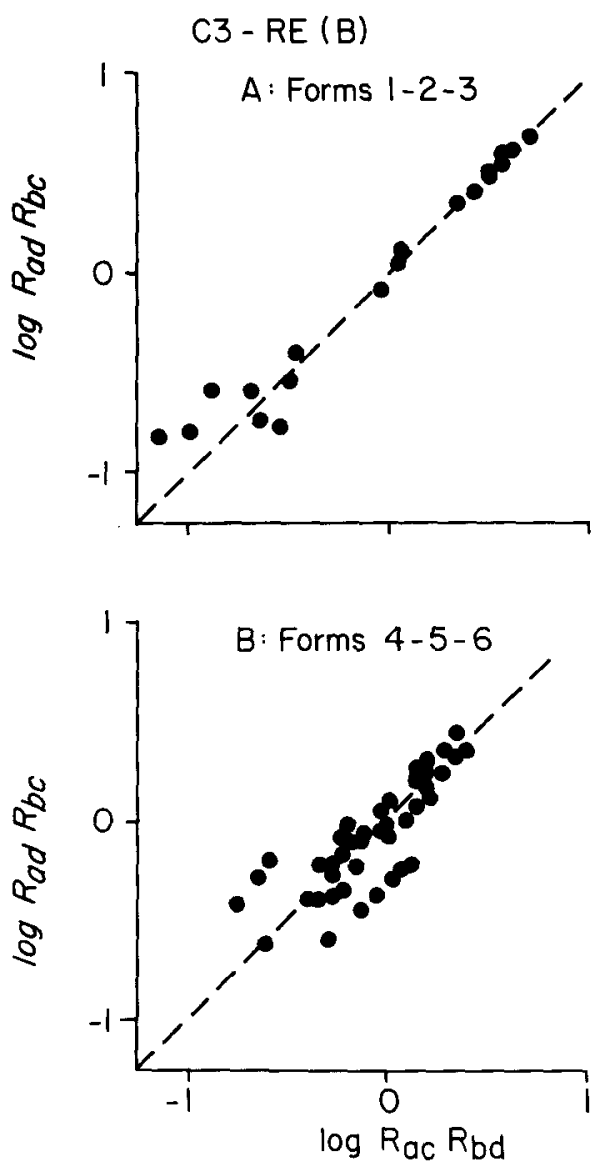

Figure 4. C3: $\log R_{a d} R_{b c}$ as a function of $\log R_{a c} R_{b d}$ for $R E(B)$. Panel A, forms 1-2-3; panel $B$, forms 4-5-6. The dashed line is the identity line $\log \mathbf{R}_{\mathrm{ad}} \mathbf{R}_{\mathrm{bc}}=\log \mathbf{R}_{\mathrm{ac}} \mathbf{R}_{\mathrm{bd}}$. Data from Engen and Levy (1955). 

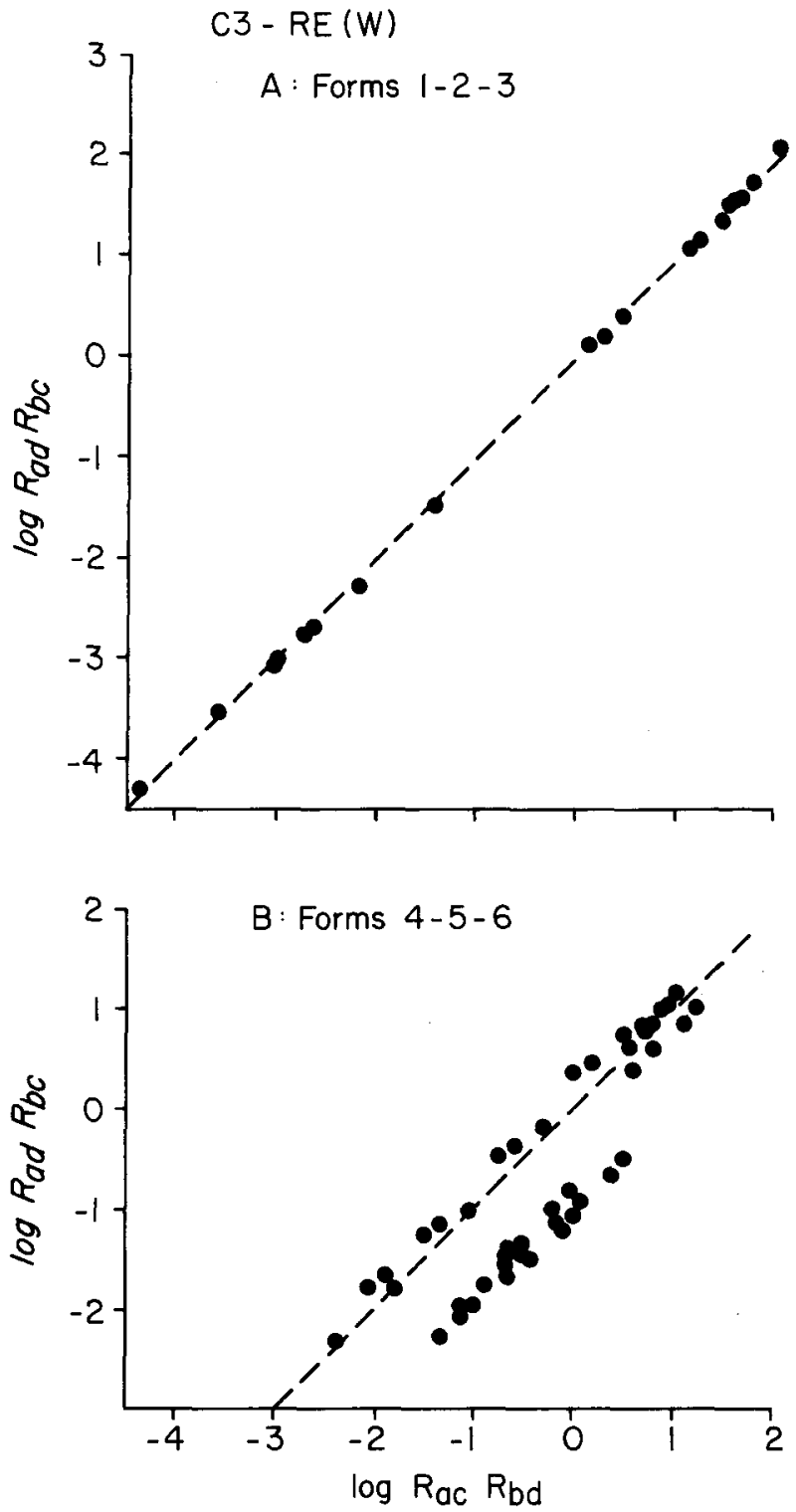

Figure 5. C3: $\log R_{a d} R_{b c}$ as a function of $\log R_{a c} R_{b d}$ for $R E(W)$. Panel A, forms 1-2-3; panel B, forms 4-5-6. The dashed line is the identity line $\log \mathbf{R}_{\mathrm{ad}} \mathbf{R}_{\mathrm{bc}}=\log \mathbf{R}_{\mathrm{ac}} \mathbf{R}_{\mathrm{bd}}$. Data from Engen and Levy (1955).

line through the origin with unit slope (dashed line). Figure 7 shows a good fit, giving further support to the RBDS model.

It might be argued that, because of the large number of parameters for the RBDS model, the good fit in Figure 7 is not compelling evidence. However, the $\alpha_{\mathrm{aL}}$ and $\alpha_{\mathrm{bH}}$ are not estimated to give the best fit to the data in Figure 7 conforming to Equation 13. Rather, the bias parameters were estimated from appropriate triples (Table 1), and hence Figure 7 represents a prediction from triples to pairs of stimuli. Nevertheless, the more convincing evidence is satisfaction of a structural condition, since such a test is parameter-free. In any event, Figure 7 is consistent with satisfaction of forms 1-2-3 of $\mathrm{C} 3$ and both give good support for the RBDS model.

\section{Bias Parameter Estimates}

Estimates of bias parameters for each model are presented in Table 6. The estimates are based on the geometric means of appropriate triples, as defined in Table 1. The number of triples used in the estimate of each $\alpha$ is indicated in the appropriate column of Table 6 labeled "N."

Since the RBDS model shows the greater consistency with all three data sets, attention is focused on the implications of the estimates for that model. Inspection of Table 6 shows that in most cases $\alpha_{\mathrm{aL}}<1$ and $\alpha_{\mathrm{bH}}>1$, the exceptions being $\alpha_{2 \mathrm{H}}=.997$ for PS(W), $\alpha_{5 \mathrm{~L}}>1$ for RE(W), and $\alpha_{5 \mathrm{H}}<1$ for RE(B). Both exceptions for ratio estimation are for the middle of the three standards, which does not show consistent biasing effects, although this exception is not present in the part-sum data. Putting aside the implications of the middle-standard exception for the moment, we consider the dominant bias directions $\alpha_{\mathrm{aL}}<1$ and $\alpha_{\mathrm{bH}}>1$.

Our first concern is a measure of consistency of the dominant directions. Since bias magnitudes on different sides of one signify opposite directional biases, a reasonable measure of consistency is the percent of triples of stimuli that estimate the bias on the dom-

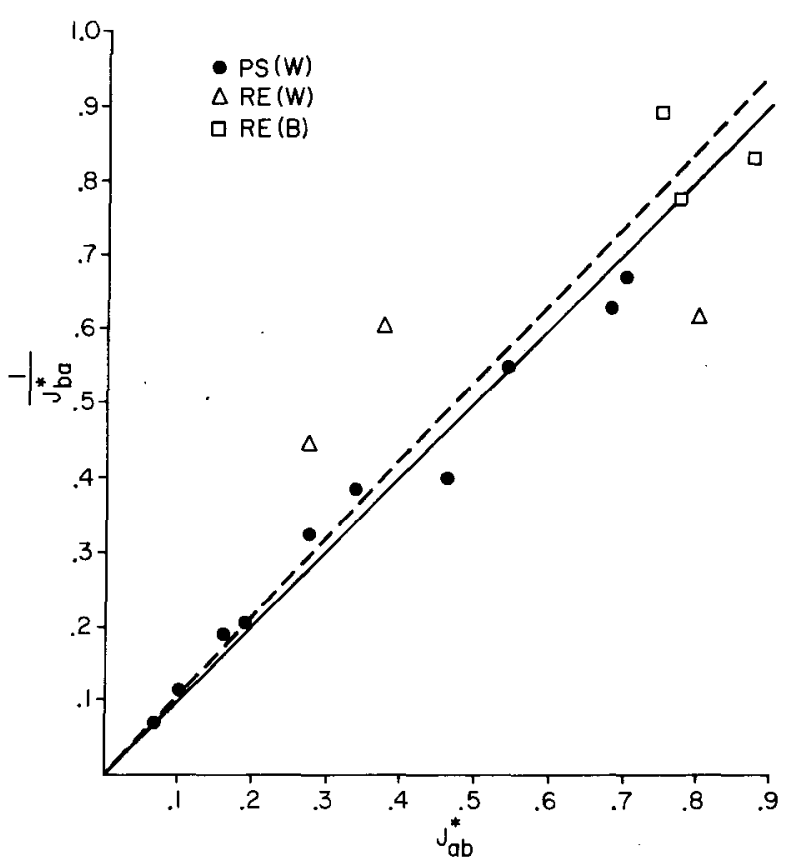

Figure 6. Reciprocal relations Models $C$ and CB: $1 / J_{b \text {, }}^{*}$ as a function of $\mathrm{J}_{\mathrm{ab}}(\mathrm{a}<\mathrm{b})$ for PS(W) (Goude, 1962), RE(B), and RE(W) (Engen \& Levy, 1955). The solid line is the identity line $1 / J_{\mathrm{ab}}^{\star}=J_{\mathrm{ab}}^{*}(C$ model $)$, and the dashed line is the function $1 / \mathbf{P}_{\mathrm{ba}}=$ $(1 / \alpha)^{2} P_{a b}^{*}[i . e .$, for PS(W) judgments only]. 


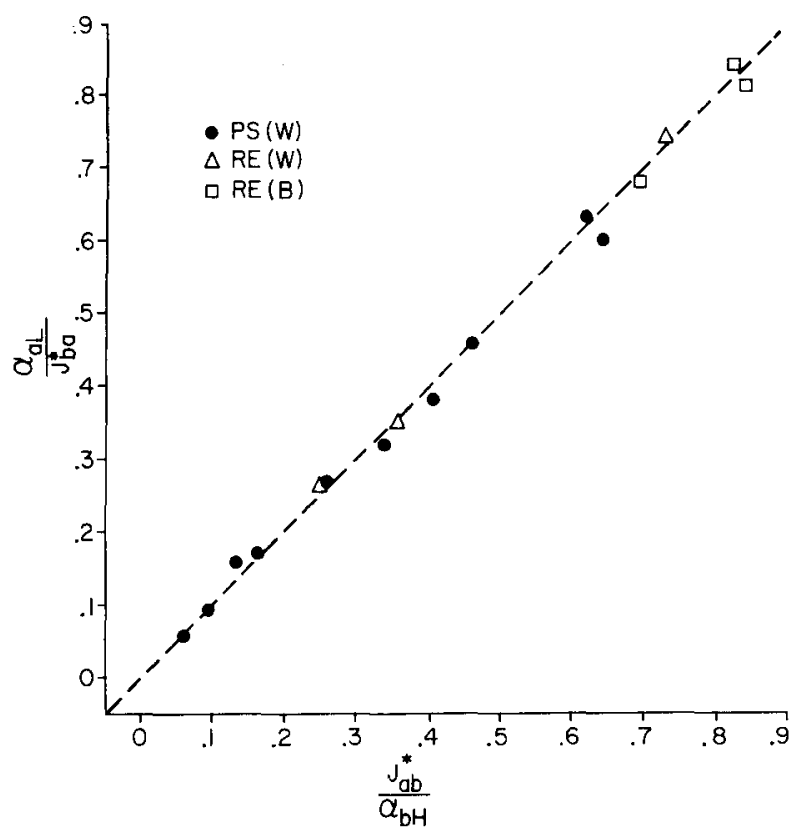

Figure 7. Reciprocal Relation Model RBDS: $\alpha_{a L} / J_{b a}^{*}$ as a function of $J_{\mathrm{ab}} / \alpha_{\mathrm{bH}}(\mathrm{a}<\mathrm{b})$ for PS(W) (Goude, 1962), RE(B) and RE(W) (Engen \& Levy, 1955). The dashed line is the identity line $\alpha_{\mathrm{aL}} / \mathrm{J}_{\mathrm{ba}}^{*}=\mathrm{J}_{\mathrm{ab}}^{*} / \alpha_{\mathrm{bH}}$.

inant side. For all three data sets combined, the results are $86.7 \%$ for $\alpha_{\mathrm{aL}}<1$ and $78.3 \%$ for $\alpha_{\mathrm{bH}}>1$. If the middle standard for RE is deleted, the percents rise to $97.2 \%$ for $\alpha_{\mathrm{aL}}<1$ and $86.1 \%$ for $\alpha_{\mathrm{bH}}>1$.

\section{Systematic Errors in C1}

Systematic errors in $\mathrm{Cl}$ are important, because this structural condition makes the appealing, though strong, measurement assumption that subjective ratios behave like numerical ratios.

Consider form 1 in Table 1 , with $\alpha^{\prime}=\mathrm{J}_{\mathrm{ab}}^{*} \mathrm{~J}_{\mathrm{bc}}^{*} / \mathrm{J}_{\mathrm{ac}}^{*}$, where $\alpha^{\prime}$ may be the bias parameter for any of the models. If (1) $\alpha^{\prime}<1$, then $\mathrm{J}_{\mathrm{ac}}^{*}>\mathrm{J}_{\mathrm{ab}}^{*} \mathrm{~J}_{\mathrm{bc}}^{*}$, and (2) if $\alpha^{\prime}>1$, then $\mathrm{J}_{\mathrm{ac}}^{*}<\mathrm{J}_{\mathrm{ab}}^{*} \mathrm{~J}_{\mathrm{bc}}^{*}$. We find that the direction of inequality is almost equally split, with $\mathrm{J}_{\mathrm{ab}}^{*}>$ $\mathrm{J}_{\mathrm{ax}}^{*} \mathrm{~J}_{\mathrm{xb}}^{*}$ (all forms) in $55.2 \%$ of the cases, combined over the three data sets. Does this mean an absence of systematic errors in $\mathrm{C} 1$ ?

Each model may give a different answer to this question. For example, the CB model does not detect systematic errors, because it fails to take into account the fact that the effects of standards may differ. We now consider how the RBDS model exposes systematic errors in $\mathrm{Cl}$ by taking into account the direction of the standard.

Consider form 3 in Table 1. According to the RBDS model, all three judgments are biased and

$$
\left(1 / \alpha_{\mathrm{aL}}\right) \mathrm{J}_{\mathrm{ba}}^{*}\left(1 / \alpha_{\mathrm{cH}}\right) \mathrm{J}_{\mathrm{ac}}^{*}=\left(1 / \alpha_{\mathrm{cH}}\right) \mathrm{J}_{\mathrm{bc}}^{*} \text {. }
$$

The biases on $\mathrm{J}_{\mathrm{ac}}^{*}$ and $\mathrm{J}_{\mathrm{bc}}^{*}$ are equal and cancel, re- ducing the parametric form of $\mathrm{Cl}$ to

$$
\left(1 / \alpha_{\mathrm{aL}}\right) \mathrm{J}_{\mathrm{ba}}^{*} \mathrm{~J}_{\mathrm{ac}}^{*}=\mathrm{J}_{\mathrm{bc}}^{*} \text {. }
$$

Hence, even though all three judgments are biased, only the bias on $\mathrm{J}_{\mathrm{ba}}^{*}$ may produce systematic errors in C1. Similarly, for form 6 the parametric form is $\left(1 / \alpha_{\mathrm{cH}}\right) \mathrm{J}_{\mathrm{bc}}^{*} \mathrm{~J}_{\mathrm{ca}}^{*}=\mathrm{J}_{\mathrm{ba}}^{*}$ and systematic errors in $\mathrm{C} 1$ occur if $\alpha_{\mathrm{cH}} \neq 1$. Given the RBDS dominant directions, (1) $\alpha_{\mathrm{aL}}<1$ and (2) $\alpha_{\mathrm{bH}}>1$, it is entailed that (1) $\mathrm{J}_{\mathrm{ab}}^{*}$ $>\mathrm{J}_{\mathrm{ax}}^{*} \mathrm{~J}_{\mathrm{xb}}^{*}$ for low effective standards (forms 2 and 3 ) and (2) $\mathrm{J}_{\mathrm{ab}}^{*}<\mathrm{J}_{\mathrm{ax}}^{*} \mathrm{~J}_{\mathrm{xb}}^{*}$ for high effective standards (forms 1 and 6). The measures of consistency for $\alpha_{\mathrm{aL}}$ and $\alpha_{\mathrm{bH}}$ given above are, of course, the measures of consistency for the two inqualities in $\mathrm{J}^{*}$. The most striking result is that with the middle stimulus deleted for $\mathrm{RE}, \mathrm{J}_{\mathrm{ab}}^{*}>\mathrm{J}_{\mathrm{ax}}^{*} \mathrm{~J}_{\mathrm{xb}}^{*}$ in $97.2 \%$ of the cases of low effective standards.

It was pointed out above that the consistent pattern of systematic errors in $\mathrm{C} 1$ in relation to high and low effective standards breaks down for the middle standard in the ratio estimation data. However, judgments relative to the middle standard were not unbiased: With respect to the low effective middle standard, RE(B) judgments were consistent with the dominant direction, but $\mathrm{RE}(\mathrm{W})$ were not; and with respect to the high effective middle standard, $\mathrm{RE}(\mathrm{W})$

Table 6

\begin{tabular}{|c|c|c|c|c|c|c|}
\hline \multirow[b]{2}{*}{ BP } & \multicolumn{2}{|c|}{ Goude (1962) } & \multicolumn{4}{|c|}{ Engen and Levy (1955) } \\
\hline & PS(W) & $N$ & $\mathrm{RE}(\mathrm{W})$ & $\mathbf{N}$ & $\mathrm{RE}(\mathrm{B})$ & $\mathbf{N}$ \\
\hline & \multicolumn{6}{|c|}{$\mathrm{CB}$} \\
\hline \multirow[t]{2}{*}{$\alpha$} & .975 & 60 & .895 & 42 & .979 & 42 \\
\hline & \multicolumn{6}{|c|}{ RBD } \\
\hline$\alpha_{\mathrm{L}}$ & .901 & 30 & .831 & 21 & .983 & 21 \\
\hline \multirow[t]{2}{*}{$\alpha_{\mathbf{H}}$} & 1.056 & 30 & .963 & 21 & .975 & 21 \\
\hline & \multicolumn{6}{|c|}{ RBS } \\
\hline$\alpha_{1}$ & .880 & 12 & & & & \\
\hline$\alpha_{2}$ & .913 & 12 & & & & \\
\hline$\alpha_{3}$ & 1.051 & 12 & .744 & 14 & .958 & 14 \\
\hline$\alpha_{4}$ & .984 & 12 & & & & \\
\hline$\alpha_{5}$ & 1.063 & 12 & 1.014 & 14 & .935 & 14 \\
\hline$\alpha_{6}$ & & & & & & \\
\hline \multirow[t]{2}{*}{$\alpha_{7}$} & & & .950 & 14 & 1.047 & 14 \\
\hline & \multicolumn{6}{|c|}{ RBDS } \\
\hline$\alpha_{1 \mathrm{~L}}$ & .831 & 6 & & & & \\
\hline$\alpha_{2 L}$ & .834 & 6 & & & & \\
\hline$\alpha_{3 L}$ & .957 & 5 & .592 & 4 & .939 & 4 \\
\hline$\alpha_{4 L}$ & .940 & 3 & & & & \\
\hline$\alpha_{5} \mathrm{~L}$ & & & 1.207 & 5 & .978 & 5 \\
\hline$\alpha_{7 \mathrm{~L}}$ & & & .957 & 4 & .976 & 4 \\
\hline$\alpha_{2 H}$ & .997 & 3 & & & & \\
\hline$\alpha_{\mathbf{3 H}}$ & 1.181 & 5 & 1.447 & 4 & 1.042 & 4 \\
\hline$\alpha_{4 H}$ & 1.053 & 6 & & & & \\
\hline$\alpha_{5} \mathbf{H}$ & 1.141 & 6 & 1.052 & 5 & .909 & 5 \\
\hline$\alpha_{7 \mathrm{H}}$ & & & 1.096 & 4 & 1.041 & 4 \\
\hline
\end{tabular}

Bias Parameter Estimates

Note $-B P=$ bias parameter $N=$ number of triples used in estimation. 
judgments were consistent with the dominant direction, but $R E(B)$ were not. The effect of the middle standard in these ratio estimation data is perplexing and warrants further study.

It was noted previously that forms 4 and 5 in Table 1 do not define a unique parameter for the RBDS model, and therefore do not entail a single low or high effective standard determining the direction of inequality in $\mathrm{C} 1$. On the other hand, the RBD model does entail a high and low effective standard for forms 4 and 5, respectively. However, the RBD model does not exhibit, in Table 6, a consistent pattern for $\alpha_{L}$ and $\alpha_{H}\left(\alpha_{L}, \alpha_{H}<1\right.$ for RE). In any event, using the empirical values obtained for $\alpha_{L}$ and $\alpha_{H}$ to determine direction for each data set separately, the measure of consistency is quite low $(62.2 \%)$.

\section{Concluding Remarks}

The $\mathrm{C}$ model assumes that judgments of comparison stimuli are not influenced by the presence of standards. This view is clearly inconsistent with these data for ratio estimation of weight and brightness, and for part-sum estimation of weight, as demonstrated by the rejection of $\mathrm{C} 1$ and the $\mathrm{C}$ model form of the reciprocal rule.

Fagot's (1978) analysis led to the rejection of the C model for unidirectional (high standard) judgments of each of the following attributes: angles and weight (Goude, 1962); brightness (Fagot, Stewart, \& Kleinknecht, 1975); velocity (Mashhour, Note 3); heaviness (Eisler, 1960); and darkness and area (Ekman, Goude, \& Waern, 1961). However, C1 was not rejected for size of circular surfaces (Ekman, 1958) and odor intensity (Engen \& Lindstrom, 1963), although for the latter the ICC was only .691 .

Fagot's (1979) study led to the rejection of $\mathrm{C} 1$ for unidimensional similarity judgments of pitch (Eisler \& Ekman, 1959), darkness and visual area (Ekman, Goude, \& Waern, 1961), and heaviness (Eisler, 1960).

Finally, Svenson and Åkesson (Note 1) found deviations from the simple reciprocal relation entailed by the $\mathrm{C}$ model for individual subjects judging area of circles and darkness. It is clear that the simplistic psychophysical view of the $C$ model must be rejected, and its value lies chiefly as a point of reference for models that place weaker constraints on the structure of the data.

The CB model assumes a constant response bias. In the present context, this implies that standards have a constant biasing effect on comparison stimuli independent of the location of the standard relative to the comparison stimulus. This view is not supported by the data for $\operatorname{RE}(\mathrm{B}), \operatorname{RE}(\mathrm{W})$, and $\mathrm{PS}(\mathrm{W})$.

Condition $\mathrm{C} 2$ has met with mixed success in the analysis of prior research on unidirectional judgments carried out by Fagot $(1978,1979)$. C2 was satisfied for ratio estimation judgments of size of circular surfaces (Ekman, 1958), velocity (Mashhour, Note 3), weight (Goude, 1962), area (Ekman, Goude, \& Waern, 1961), and odor intensity (Engen \& Lindstrom, 1963). C2 was also satisfied for unidimensional similarity estimates of pitch (Eisler \& Ekman, 1959), visual area (Ekman, Goude, \& Waern, 1961), and heaviness (Eisler, 1960). However, C2 was rejected for ratio estimation judgments of angles (Goude, 1962), brightness (Fagot, Stewart, \& Kleinknecht, 1975), heaviness (Eisler, 1960), and darkness (Ekman, Goude, \& Waern, 1961). C2 was also rejected for unidimensional similarity estimates of darkness (Ekman, Goude, \& Waern, 1961).

In all of the studies cited above analyzed by Fagot (1978, 1979), the judgments were, as stated, unidirectional (high standard). It is not surprising that $\mathrm{C} 2$ fares better with unidirectional judgments, since the direction of the standard clearly affects judgments of comparison stimuli. The CB model is best viewed as an approximation to the RBS or RBDS model, in which the bias parameter in the CB model is the average of the bias parameters of the various standards. That approximation is going to be best when judgments are unidirectional and standards are closely spaced, and poor for bidirectional judgments and widely spaced standards.

The RBD model entails that two directional biases are operative, one for comparison stimuli above the standard and another for comparison stimuli below the standard. This is an appealingly simple conception, but one that is not supported by the data on PS(W), RE(W), and RE(B). The data analyzed by Fagot $(1978,1979)$ were unidirectional, and do not therefore provide test data for the RBD model.

The RBS model does not explicitly take account of the direction of the standard relative to the comparison stimulus, but does permit each standard to have a different biasing effect. The RBS model is supported by the part-sum data, but does not fare as well for the ratio estimation data as the RBDS model. The unidirectional ratio estimation data (Fagot, 1978) and similarity data (Fagot, 1979) were generally supportive of $\mathrm{C} 3$ and therefore the RBS model. It would appear that the RBS model fares extremely well with unidirectional judgments, but does not give a good account of bidirectional judgments because of the obvious failure to incorporate assumptions relating to the direction of the standard.

The RBDS model entails that each standard has two biasing effects depending on the location of the standard above or below the comparison stimulus. The PS(W), RE(B), and $R E(W)$ data are strongly supportive of the RBDS model, as can be seen from the fit displayed in the A panels of Figures 3, 4, and 5 and in Figure 7. The unidirectional data (Fagot, 1978, 1979) were also consistent with the RBDS model, but cannot, of course, be used to choose between the RBS 
and RBDS models, since both models have precisely the same entailments for unidirectional judgments (form 1 or form 2 of $\mathrm{C} 3$, Table 3).

The $\mathrm{C}$ model makes the erroneous measurement assumption that subjective ratios behave like numerical ratios, that is, that $\mathrm{J}_{\mathrm{ab}}^{*}=\mathrm{J}_{\mathrm{ax}}^{*} \mathrm{~J}_{\mathrm{xb}}^{*}$. The RBDS model shows that, in general, (1) for low effective standards, $\alpha_{a L}<1$ and $\mathrm{J}_{\mathrm{ab}}^{*}>\mathrm{J}_{\mathrm{ax}}^{*} \mathrm{~J}_{\mathrm{xb}}^{*}$, and (2) for high effective standards, $\alpha_{\mathrm{bH}}>1$ and $\mathrm{J}_{\mathrm{ab}}^{*}<\mathrm{J}_{\mathrm{ax}}^{*} \mathrm{~J}_{\mathrm{xb}}^{*}$. The unidirectional data (high standard) examined by Fagot $(1978,1979)$ were highly consistent with Case 2. Only for similarity judgments of pitch (Eisler \& Ekman, 1959) was there a clear reversal $\left(S_{a b}^{*}>\right.$ $\mathrm{S}_{\mathrm{ax}}^{*} \mathrm{~S}_{\mathrm{xb}}^{*}$ ).

The bias parameters may be interpreted as measuring the effect on scale values of using an incorrect model. For example, the error in estimating $\Psi_{a} / \Psi_{b}$ using the $\mathrm{C}$ model, given that the RBDS model is correct, is $\alpha_{\mathrm{bH}}-1(\mathrm{~b}>\mathrm{a})$ or $\alpha_{\mathrm{bL}}-1(\mathrm{~b}<\mathrm{a})$. Table 6 shows that the errors are in some cases quite large. The largest errors are for standard 3, RE(W): $40.8 \%$ for the low standard and $44.7 \%$ for the high standard.

According to the RBDS model and the dominant bias directions, $\mathrm{J}_{\mathrm{ab}}^{*}$ overestimates the sensory ratio $\Psi_{\mathrm{a}} / \Psi_{\mathrm{b}}$ and $\mathrm{J}_{\mathrm{ba}}^{*}$ underestimates $\Psi_{\mathrm{b}} / \Psi_{\mathrm{a}}$ (that is, $\mathrm{J}_{\mathrm{ba}}^{*}$ overestimates $\left.\Psi_{\mathrm{a}} / \Psi_{\mathrm{b}}\right)$. Hence, low and high effective standards are consistent in their biasing effects, both effecting overestimation of the sensory ratio $\Psi_{a} / \Psi_{b}$. However, the biasing effect of low standards tends to be larger than that of high standards, since, in the majority of cases, $\alpha_{\mathrm{aL}} \alpha_{\mathrm{bH}}<1$. For ratio estimation, this means that fractional judgments (high standard) tend to be less biased than multiple judgments (low standard). The directional biases for low and high effective standards are consistent with the hypothesis of an assimilation effect, which implies that the "true" separation between the two stimuli of a presentation pair is attenuated by bias.

The analysis of ratio estimation with a high standard by Fagot (1978) indicated a tendency for $\alpha_{b H}$ to decrease with the increasing magnitude of the standard, implying, since $\alpha_{\mathrm{bH}}>1$, a decrease in biasing effect as the magnitude of the high standard increases. This tendency is not apparent in the PS(W) data, but the RE(W) and RE(B) data are consistent with this tendency provided the troublesome middle standard is deleted (Table 6).

It is hypothesized that for low effective standards, $\alpha_{\mathrm{aL}}$ increases with increasing magnitude of the standard, implying, since $\alpha_{\mathrm{aL}}<1$, a decrease in biasing effect as the magnitude of the low standard increases. This hypothesis receives partial support from the data of Table 6, but for $\mathrm{RE}(\mathrm{W})$ data, the ordering is disrupted for the middle standard.

Note that, for both low and high effective standards, the hypothesized ordering on $\alpha_{\mathrm{bH}}$ and $\alpha_{\mathrm{aL}}$ implies a decrease in biasing effect as the magnitude of the standard increases (i.e., as the separation between comparison and standard increases). It appears to be like a magnetic attraction for which the effect decreases with distance. In any event, further support for this hypothesis is needed, especially with individual subjects, and the role of the middle standard must be investigated.

Special features of the theory of relative judgment presented in this paper and in Fagot $(1978,1979)$ are: (1) parameter-free testing of structural conditions, (2) nesting of alternative models, and (3) applicability to a variety of judgmental methods. The nesting of models involves a progressive weakening of the constraints placed on the structure of the data, permitting a search for the strongest model consistent with the data. The theory has the generality to apply to any judgmental method for which an appropriate response transformation can be found, and this has been done for unidimensional similarity judgments (Eisler \& Ekman, 1959) and part-sum estimation (Goude, 1962). For ratio estimation, of course, the response transformation is the identity function $\left(\mathrm{J}_{\mathrm{ab}}^{*}=\mathbf{R}_{\mathrm{ab}}\right)$.

For bidirectional judgments, it was found that only the RBDS model was acceptable for all three data sets-RE(B), RE(W), and PS(W). Given satisfaction of the testable consequences of the RBDS model, a ratio scale may be constructed using Equation 13.

\section{REFERENCE NOTES}

1. Svenson, O., \& Åkesson, C. A. Fractional and multiple estimates in ratio scaling. Reports from the Psychological Laboratories, The University of Stockholm, No. 202, January 1966.

2. Svenson, O., \& Ákesson, C. A. A further note on fractional and multiple estimates in ratio scaling. Reports from the Psychological Laboratories, The University of Stockholm, No. 224, February 1967.

3. Mashhour, M. On the validity of scales derived by ratio and magnitude estimation methods. Reports from the Psychology Laboratory, University of Stockholm, No. 105, 1961.

\section{REFERENCES}

BAятко, J. J. On various intraclass correlation reliability coefficients. Psychological Bulletin, 1976, 83, 762-765.

Comrey, A. L. A proposed method for absolute ratio scaling. Psychometrika, 1950, 15, 317-325.

EISLER, H. Similarity in the continuum of heaviness with some methodological and theoretical considerations. Scandinavian Journal of Psychology, 1960, 1, 69-81.

Eislen, H., \& Exman, G. A mechanism of subjective similarity. Acta Psychologica, 1959, 16, 1-10.

Ekman, G. Two generalized ratio scaling methods. Journal of Psychology, 1958, 45, 287-295.

Emman, G., Goude, G., \& Waern, Y. Subjective similarity in two perceptual continua. Journal of Experimental Psychology, $1961,61,222-227$.

EngEN, T., \& Levy, N. The influence of standards on psychophysical judgments. Perceptual and Motor Skills, 1955, 5, 193197. 
Engen, T., \& Lindström, C. O. Psychophysical scales of the odor intensity of amyl acetate. Scandinavian Journal of Psychology, 1963, 4, 23-28.

Engen, T., \& Ross, B. M. Effect of reference number on magnitude estimation. Perception \& Psychophysics, 1966, 1, 74-76.

FAGOT, R. F. A theory of relative judgment. Perception \& Psychophysics, 1978, 24, 243-252.

FAGOT, R. F. Nested models of relative judgment: Applications to a similarity averaging model. Perception \& Psychophysics, 1979, 26, 255-264.

Fagot, R. F., Stewart, M. R., \& Kleinknecht, R. E. Representations for biased numerical judgments. Perception \& Psychophysics, 1975, 17, 309-319.

GouDE, G. On fundamental measurement in psychology. Stockholm: Almqvist \& Wiksell, 1962.

Jones, F. N., \& Woskow, M. J. Some effects of context on the slope in magnitude estimation. Journal of Experimental Psychology, 1966, 71, 177-180.

Macmillan, N., Moschetto, C., Bialostozky, F., \& Engel, L. Size judgment: The presence of a standard increases the exponent of the power law. Perception \& Psychophysics, 1974, $16,340-346$.

Poulton, E. C. The new psychophysics: Six models for magnitude estimation. Psychological Bulletin, 1968, 69, 1-19.

Ross, J., \& DiLollo, V. A consistent failure of the power law for lifted weights. Perception \& Psychophysics, 1970, 8, 289-290.

Shrout, P. E., \& Fleiss, J. L. Intraclass correlations: Uses in assessing rater reliability. Psychological Bulletin, 1979, 86, 420-428.

Siegel, S. Non-parametric statistics. New York: McGraw-Hill, 1956.

\section{NOTES}

1. Svenson \& $\AA$ kesson (Note 1, Note 2) used the term "reciprocal asymmetry" for our "reciprocal relation."

2. Note that $\mathrm{H}_{0}(\mathrm{C} 1)$ and $\mathrm{H}_{0}(\mathrm{C} 2)$ are expressed in product form, whereas $\mathrm{H}_{0}(\mathrm{C} 3)$ is expressed in ratio form. $\mathrm{H}_{0}(\mathrm{C} 3)$ can be stated in ratio form only for $k \geqslant 3$, but may be stated in the product form for $k=2, J_{a 1}^{*} J_{b 2}^{*}=J_{22}^{*} J_{b 1}^{*}$. For $k=2, H_{0}(C 3)$ was stated in product form for statistical tests and plots to obtain comparability in form to $\mathrm{C} 1$ and $\mathrm{C} 2$. Since $\log \mathrm{J}^{*}$ was used as the dependent variable, the statistical tests were invariant under change in form (product or ratio), but the plots were made more comparable by using the product form of $\mathrm{C} 3$.

3. The ICC measure used was $\operatorname{ICC}(3,1)$, corresponding to Case 3 as defined by Shrout and Fleiss (1979). However, for these data the ICCs are high enough for it to make little difference which ICC measure is used.

4. The range of the brightness judgments was much smaller than the range of the weight judgments, and hence, for display purposes, different scales were used in Figures 1 and 2 [since the point of the figures was not to compare RE(W) and RE(B)]. The mean squared deviations about the identity line for weight were, in fact, about 10 times larger than for brightness.

5. To avoid possible confusion brought on by the labeling of the axes in Figure 3, and Figures 4 and 5 to follow, it should be pointed out that no specific ordering on $a, b, c, d$ is implied: The ordering will vary with the form of $\mathrm{C} 3$.

6 . Figures 4 and 5 should not be compared directly, since the scale of Figure 3 is about six times that of Figure 4 (see Footnote 4). However, the comparability of the ICCs serves to correct for this scale difference.

(Manuscript received January 26, 1981;

revision accepted for publication May 8, 1981.) 